\title{
Classification of the Written Reports Used in Experimental Engineering
}

\author{
Sheldon M. Jeter and Jeffrey A. Donnell \\ Georgia Institute of Technology
}

\section{INTRODUCTION}

Laboratory instructors strive continuously to improve the writing of undergraduate lab reports, and success requires a communal effort by several instructors and many students. To allow coordinated instruction, the faculty must define the learning objectives and agree on a common instructional strategy. Students can then be guided in a consistent fashion toward proficient technical writing. This guidance should include a manual incorporating a uniform writing standard that represents industrial and academic practice. Instruction can then refer to a single consensus standard. Consistent grading and feedback based on this standard can then reinforce the instruction. However, the instruction cannot be planned, nor the writing standard be developed without a practical objective. The practical objective is the kind of technical writing and production quality that fits the needs of the curriculum and professional practice and that can be expected from undergraduates. The objective is defined in terms of representative report types and the corresponding contents, formats, and production qualities. Without such a common and well defined objective, successive instructors will waste time and frustrate the students by presenting and requiring report types and production qualities that differ only marginally from the consensus standards while generating continual confusion.

In learning report writing, the student learns a process. The student's objective is proficiency in the process of efficient preparation of effective technical reports. In learning a process, a functional description of the ultimate acceptable product is almost essential if proficiency is to be achieved. An effective report is one that is complete, concise, and convincing in the communication of technical information. The presentation should be orderly, and the format should be familiar and reassuring to the reader. A key component of the description of the product is a classification of the types of reports that engineers are likely to produce. Once the types are identified, it is straightforward to define standards for format and production qualities that represent typical academic and professional practice.

Definition of a few comprehensive report types will also alleviate an objection that is one of the most persistent obstacles to an orderly process of instruction in report writing. Since very many report types exist in practice, it is objected that requiring only one type is in the curriculum is improper. Consequently, it becomes unnecessarily difficult to teach report writing because the instruction cannot be consistent and reinforced. To overcome this objection, it is demonstrated that all practical report types are mere variations on a very few general types and that these types can be taught and practiced within one curriculum. The ancillary objection that format, styles, 
and production qualities differ from one organization or affiliation to another can be similarly countered by pointing out that nothing prevents a common set of representative standards from being adopted for the purpose of instruction. After some academic practice, students will recognize the prevalence and importance of such standards and find it easy to adjust to another set in professional practice or just continue to use the instructional set if no specific alternative guidance is given.

Further, once the set of standards is developed, they can readily be incorporated into a process of instruction on writing that is linked to the sequence of laboratory courses in the curriculum. The writing instruction can be staged in such a way that the complexity of the reports correlates with the increasing complexity of the projects in the advancing courses. The result is an instructional program that challenges the students with higher levels of complexity and responsibility while acquainting them with the range of reports in everyday use.

\section{BACKGROUND}

One of the most common misperceptions about undergraduate engineering students is that they have had the occasion to become familiar with professional engineering reports. While all faculty members have spent years perusing the technical literature and have had guidance on writing from experienced advisors and editors, few undergraduate students have reviewed much primary literature before they enter their engineering laboratory courses. Fewer still have come to understand the kind of structural and stylistic concerns that drive professional engineering reporting. In fact, there is every reason to assume that their prior writing instruction may have been unhelpful if not downright confusing. On one hand, general writing instruction may be irrelevant to specific practice (Petraglia, 1995). One the other hand, context specific instruction may be limited to business applications. For example laboratory reports are, quite properly, omitted from one list of "every conceivable business document" commonly presented in communications textbooks (Thomas, 1995). Indeed, a typical technical writing textbook, such as Carosso's (1986) popular text, provide models of business reports, but not laboratory reports. Further review of the literature reveals no current texts - either in experimental engineering or in writing instruction - that explicitly describe the acceptable appearance of a lab report. This omission is despite the acknowledged importance of page design, graphics, and illustrations (Markel, 1995). Further, we know of no introductory courses - in engineering or in writing - that require students to read engineering reports or publications for any reason. In fact, a recent survey of 35 of our senior students revealed that 17 (48\%) had never read a professional level report and that only 14 (40\%) had read more than one.

Because our students do not bring a strong understanding of professional level experimental report writing with them into the classroom, we found that our faculty colleagues struggled constantly, and piecemeal, to teach writing informally. We found our students to be generally unprepared to begin writing professional-quality reports and unable to correlate the reporting requirements of their different courses and instructors. Consequently, we found that both groups used time inefficiently, with our students dithering endlessly over minutiae and our colleagues explaining trivia at great length.

To solve these problems, our faculty determined to embrace a program of explicit instruction in lab report writing. This approach does not rely on general skills that may not be present and focuses limited resources on a well defined context. For our program to function 
properly we needed to coordinate our teaching of the report-writing processes. This coordination must consider the relationships among the courses in our laboratory sequence and the corresponding variation in required reports. All good reports will contain a core of information that is basic to any experimental project; but the particular type must adapt to variations in the project, such as the scope of the work, the complexity of the project and the independence granted to the student investigators. Successful coordination requires definition of these report types as they vary in response to the different laboratory projects, which in turn are designed to simulate projects the students might encounter in practice. Classification of the report types is thus seen to be critical to coordination of the instruction.

\section{CLASSIFICATION}

By review of the literature, consideration of personal experiences, and discussion with practitioners, one reasonably logical and functional classification of reports has been developed. The classification forms a natural and systematic hierarchy of reports that has at least two desirable features. One feature is functional. The principal types of reports conform well to the needs of a typical undergraduate curriculum and to professional practice. The other feature is instructional. By following the hierarchy, students will encounter more sophisticated challenges at every level. As these challenges are mastered, the students naturally improve their capacity to plan and compose technical reports at the next level. An unexpected byproduct of this classification exercise was an improved perspective on how to teach technical writing.

Three basic types of reports were first found to exist. Abstracts are essentially reports about reports. Itemized reports are rigidly structured presentations of the results of similarly tightly structured experimental procedures. Finally, narrative reports recite all the essential features, findings, and conclusions of an experiment or project. Abstracts include technical abstracts that accompany and define a much longer narrative report and extended abstracts that typically serve as a condensed written record of a somewhat longer oral and visual presentation. A narrative report tells the story of an experiment. This attribute explains the name. Narrative reports may be short reports in letter format or longer reports depending on the extent of the investigation and the scope of the report. Narrative reports may be narrowly circulated or more widely published. A published short report might be published as a technical note in a journal. A somewhat longer narrative report might appear as a journal article or as a monograph.

It is probably not entirely fortuitous that this hierarchy of reports admirably suits a typical undergraduate lab curriculum. For example, at Georgia Tech students begin with an introductory instrumentation and methods course. An itemized report is ideally suited for reporting the results and observations from the highly structured measurement exercises in such a course. The next course is an engineering sciences and systems lab. The short narrative written report is used for some experiments while an extended abstract accompanies the oral and visual presentation on others. Student writing and composition skills improve as they move from the more prescribed itemized report to the short narrative report, which demands more sophisticated individual input. Finally students are prepared to plan and conduct a semester long experimental project and are similarly prepared to plan and compose a long narrative report of this project.

\section{GENERAL CONTENT}

Most technical professionals rightly describe reports in terms of format. However, while format is a useful form of shorthand for experienced technical readers, it does not guide the 
novice writer who still must learn that report format is driven by the information to be presented in the report. This small distinction is important to undergraduates since students can misunderstand different faculty members' abstract descriptions of required formats. In contrast, we find that this confusion is alleviated when we define our descriptions of report formats in terms of information content. Using this principle, we developed a general topical outline based on the way technical readers seem to prefer to see information arranged in a typical lab report. We then developed a list of standard descriptive headings to be linked to each information element, and we created for each such heading a list of prompt questions, whose answers could provide the minimum necessary amount of information for each section in our reports.

Our topical list and its associated prompt questions are designed to provide the information core for any experimental report. Different reports and different classes will diverge from this standard report core to the extent that they require more or less detail or discussion from the author. Generally speaking, students in their first experimental courses will prepare short reports, while more advanced students will be expected to show their expertise in increasingly detailed discussions and analyses on projects of increasing complexity. In practice, thus, our novice engineers first prepare very simple reports, which we call itemized reports. More experienced students prepare extended abstracts and short narrative reports, which build on the itemized report format while providing more analysis and discussion. In our capstone experimental course, the students are asked to write reports that provide the detailed analysis and discussion expected in a longer narrative report. This booklet length report typically includes a problem statement, a fully researched background section, and a lengthy discussion of methods.

The general outline of any report in our hierarchy of reports is organized around the set of section headings shown in Table 1 with associated suggestive prompt questions.

Table 1. Typical Section Headings and Associated Prompt Questions

\begin{tabular}{|l|l|}
\hline \multicolumn{1}{|c|}{$\begin{array}{c}\text { Section } \\
\text { Heading }\end{array}$} & \multicolumn{1}{c|}{ Prompt Question } \\
\hline Objectives & $\begin{array}{l}\text { What was the goal of the investigation? } \\
\text { What values or relationships were determined? }\end{array}$ \\
\hline Background & $\begin{array}{l}\text { What is the importance or application of this work? } \\
\text { What is the supporting theory or previous work? }\end{array}$ \\
\hline $\begin{array}{l}\text { Apparatus and } \\
\text { Procedures }\end{array}$ & $\begin{array}{l}\text { What instrumentation and equipment were used? } \\
\text { How accurate were the instruments, and how were they calibrated? } \\
\text { What was examined, and how was this examination conducted? }\end{array}$ \\
\hline $\begin{array}{l}\text { Data or } \\
\text { Findings }\end{array}$ & $\begin{array}{l}\text { What data were obtained for each experimental task? } \\
\text { How are the data best summarized and/or displayed? }\end{array}$ \\
\hline Analysis & $\begin{array}{l}\text { How were the data processed? What inferred data were generated? } \\
\text { What formulas, algorithms, or models were used? } \\
\text { What summary data or results were drawn from this analysis? }\end{array}$ \\
\hline Discussion & $\begin{array}{l}\text { How do the data compare with theoretical or literature values? } \\
\text { How can discrepancies with expected values be explained? } \\
\text { What conclusions can be drawn from this task? }\end{array}$ \\
\hline Closure & What conclusions should be reported in this paper? \\
\hline
\end{tabular}


The general content and outline we adopted after some independent consideration is, as expected, similar to outlines already proposed in the literature (e.g., Tuve and Domholdt, 1966). Such established precedent is reassuring when advocating a standard tool to undergraduates. This information core is flexible because it is driven by the requirements of the project. Indeed, the background section is usually omitted until our experimental project course. Consequently, this information-driven approach to composition can be used by the student, or by an instructor, as a tool to outline any report in preparation or a check on the organization of any completed report. The report for a project of any size can be readily outlined once the project has been partitioned into its constituent tasks. The information core determines the substantive outline of the report. The format of the physical realization of the report depends on the scope of the project. The four report formats used in our course sequence are described below.

\section{ITEMIZED REPORTS}

Itemized reports are rigidly structured presentations of the results of similarly tightly structured experimental procedures. Typically a supervising engineer will outline an itemized report as a sequence of required measurements and calculations to be routinely executed by a junior engineer or technician. An example application may be to implement a test in accord with an ASTM standard or an ASME Performance Test Code. The report usually consists of a numbered paragraph, or section, for each and every required step. The itemized report is often overlooked in college-level instruction, but it is an effective tool for an efficient and convincing presentation. In an undergraduate curriculum, the itemized report is a useful way of introducing and exemplifying orderly report writing, and its highly structured format can facilitate efficient grading and feedback. The information core for an itemized report is always defined by the supervising author to fit the prevailing needs. The itemized report can be selective in its content because of its restricted scope. Much use of this type is made in our introductory course. A typical experiment is documented with an itemized report containing paragraphs describing the following typical content: objective, apparatus and procedure, data analysis, discussion, and closure. Another use is to document a pre-lab exercise that is often required in our intermediate course to demonstrate that the students have prepared for an experiment. An example itemized pre-lab report that illustrates this format is given in Appendix I.

\section{EXTENDED ABSTRACTS}

An extended abstract is a hybrid of a narrative report with a technical abstract that is written to accompany and document an oral and visual presentation. In our second laboratory course, students are asked to examine and characterize more complicated systems and to compare their observations with well-known models of these systems. For some of these experiments, students are asked to prepare extended abstracts to accompany an oral and visual presentation. Just as the familiar technical abstract notifies readers of what information can be found in the written report, the extended abstract notifies audience members of what information will be presented in the talk. It differs in that it includes in a very condensed fashion the principal contents of the full presentation. Students can expect to prepare such abstracts to accompany presentations to managers and supervisors who must review numerous reports and to accompany presentations to some professional meetings.

The extend abstract differs from the standard technical abstract in that it can be longer, it can refer directly to the presentation it describes, it can include figures in the text, and it can even 
have attachments. In fact is has then same core content as the full report or presentation but in a more condensed version. An example is given in Appendix II.

\section{SHORT NARRATIVE REPORT}

Finally, narrative reports recite all the essential features, findings, and conclusions of an experiment or project. A narrative report tells the story of an experiment. This attribute explains the name. Narrative reports may be short reports in letter format or longer reports depending on the extent of the investigation and the scope of the report. Narrative reports may be narrowly circulated or more widely published. A short report might be published as a technical note or article in a journal. The short narrative report is important professionally because it is complete enough to be reviewed but not too long for widespread publication.

Many undergraduate and professional projects require shorter narrative reports in the well-known letter or memorandum format. For many of the experiments in our second course, students are asked to prepare only a written report, and the short memorandum report is the appropriate format. An example of this type follows as Appendix III. The typical short report is organized into several brief sections in accord with the general content discussed above. Each section may be as short as a single paragraph. For student assignments, each section of the report addresses a topic usually specified or implied in the lab manual. These topics are based on our common information core. In fact this report may be the most representative example. Note that higher standards of detail are expected in each section than the itemized report, which is deliberately constrained, or the extended abstract, which is deliberately condensed.

\section{LONGER NARRATIVE REPORT}

A long narrative report is hardly different in concept from a short report except the sections are typically expanded into major section or even chapters or volumes with their own subdivisions. A separate technical abstract is almost always required. The letter format is clearly unsuitable; however, a cover letter of transmittal is sometimes appropriate. A long report should always have a formal cover page, which should be in accordance with the ISO standard (ISO, 1982). Such a report may be separately published as a monograph.

In our curriculum, students plan and conduct a semester long experimental project in their third lab course. By this time, their practice with itemized and memorandum reports has prepared them to plan and compose a long narrative report of this project. The scope of the project demands a background section. Obviously no example of this type is included here. Indeed, for economy the example prepared for our students in the experimental project course is web based not printed.

\section{DISCUSSION}

Defining the types of reports appropriate to and anticipated in the undergraduate curriculum has been a constructive exercise. We envision that dissemination of our instructional tools, a style and standards manual and a set of model reports, based on this definition will have an important impact on our program of technical communication. First, our manual explicitly describes for the students our expectations for style and general content in reports at the different levels in our curriculum. Second, this exercise has helped us to articulate, both for ourselves and for our teaching assistants, the specific standards to be used for writing and for evaluating written reports. These consensus standards make it possible to coordinate the kinds of feedback the 
students receive on their reports, a consistency that should promote a perception that our grading systems are applied fairly and equally and toward a rational and useful end.

Finally, and most importantly, our instructional tools provide the faculty with a specific set of reference points to use when they discuss communications issues with their students. It is not absolutely necessary for all faculty members to follow our guidelines completely; such conformity is seldom obtained and may not be desired. But our guidelines provide a welldocumented and fully characterized set of references on style and standards. These references can be used effectively as models or as points of departure for project reports that may call for modifications to our core of basic reporting information. We seek to provide a concrete starting point in order to facilitate such modifications, not in order to close discussions of professional writing. Based on our experience, we advocate that every engineering department develop or adopt a similar set of writing and report standards based on explicit examples of the reports expected to be generated by their students, and we further propose the set of reports described herein as one representative set of examples.

\section{REFERENCES}

Carosso, R. B., 1986, Technical Communication, Wadsworth, Inc, Belmont, California.

ISO, International Organization for Standardization, 1982, "Documentation - Presentation of scientific and technical reports", International Organization for Standardization, Geneva, 15 March 1982.

Markel, M., 1995, "Using Design Principles to Teach Technical Communication," Journal of Business and Technical Communication, Vol. 9, No. 2, pp. 206-218.

Petraglia, J., 1995, "General Writing Skills Instruction and its Discontents", Reconceiving Writing, Rethinking Writing Instruction, Lawrence Erlbaum and Associates, Mahwah, N. J.

Thomas, S., 1995, "Preparing Business Students more Effectively for Real-World Communication", Journal of Business and Technical Communication, Vol. 9, No. 4, pp. 461-474.

Tuve, G. L. and L. C., Domholdt, 1966, Engineering Experimentation, McGraw-Hill, New York.

SHELDON M. JETER is Associate Professor of Mechanical Engineering at the George W. Woodruff School of Mechanical Engineering at Georgia Tech. He has degrees from Clemson University, the University of Florida, and Georgia Tech. He has been on the academic faculty at Georgia Tech since 1979. His research interests are thermodynamics, heat and mass transfer, and energy systems.

JEFFREY A. DONNELL is Coordinator of the Frank K. Webb Program in Professional Communication at the George W. Woodruff School of Mechanical Engineering at Georgia Tech. His degrees are from Washington University and Emory University. He has been on the faculty at Georgia Tech since 1992. His professional interests are composition and rhetoric. 
TO: ME 4053 Instructional Staff

24 August 1999

FROM: ME 4053 Section A7, Group 2: G. Burdell, G.-P. Burdelle, and J. Perez, SUBJECT: Prelab Report for Calorimeter Experiment

1. Experimental Spreadsheet. Sample experimental data was provided. An EXCEL spreadsheet has been designed and implemented to receive and process the experimental data. A block of the pertinent example data is reproduced below as Table 1 .

Paragraph heading sufficient when every section is one paragraph
Table 1. Heat Capacity Data and Model

\begin{tabular}{|c|c|c|}
\hline Temp & Data & Model \\
\hline $\mathrm{C}$ & $\mathrm{J} / \mathrm{kg}-\mathrm{K}$ & $\mathrm{J} / \mathrm{kg}-\mathrm{K}$ \\
\hline 10.1 & 2005 & 2000 \\
\hline 20.0 & 2030 & 2041 \\
\hline 29.9 & 2105 & 2100 \\
\hline 40.2 & 2180 & 2182 \\
\hline 50.0 & 2285 & 2278 \\
\hline 59.9 & 2390 & 2394 \\
\hline
\end{tabular}

2. Regression Modeling. A regression model of the form,

$$
C_{p}=\left(\frac{d h}{d T}\right)_{P}=C_{0}+B_{1} T+B_{2} T^{2}
$$

has been developed for the representative data. The model and the sample data are illustrated in Figure 1.

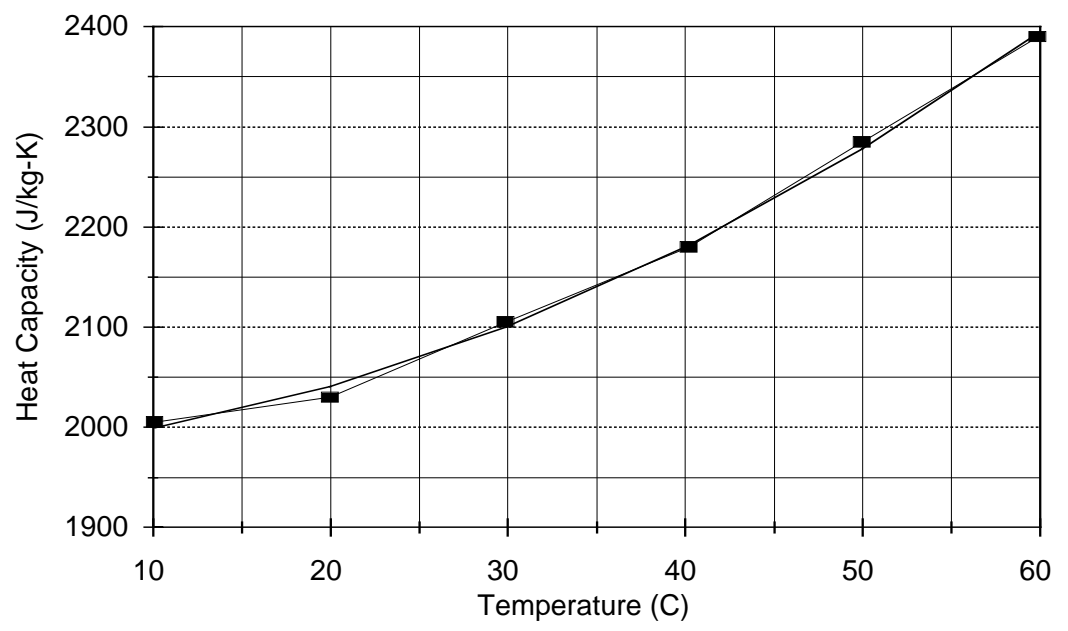

Figure 1. Heat Capacity Data (markers) and Model (line). 
Investigation of Pipe Flow Using the Laser Doppler Velocimeter (LDV)

by G.P. Burdell and Georges Burdello

for ME 4053 Engineering Systems Laboratory

Presented 22 July 1999

Introduction. The flow of water in a circular pipe was investigated using an LDV on 8 July 1999 in the Thermal Sciences Instructional Lab of the School of Mechanical Engineering at Georgia Tech. The full oral and visual presentation addresses detailed findings and overall conclusions of this investigation.

Procedure and Apparatus. The water flow loop consists of a circulating pump, controls, and auxiliary piping supplying a nearly constant flow to a $25 \mathrm{~mm}$ (1.0 inch) inner diameter glass pipe. The system and its components are described in the full presentation. The velocity profile was conducted by traversing the measurement volume of the differential Doppler LDV (TSI System 9100) diametrically between the inner walls of the pipe at $2.5 \mathrm{~mm}$ (nominally 0.10 inch) intervals.

Data and Findings. Velocity and turbulence intensity data were collected and are provided in the full report. Some representative data are summarized in Table 1.

Table 1. Representative Velocity Statistics

\begin{tabular}{|c|c|c|}
\hline $\begin{array}{c}\text { Wall } \\
\text { Distance } \\
(\mathrm{mm})\end{array}$ & $\begin{array}{c}\text { Mean } \\
\text { Velocity } \\
(\mathrm{m} / \mathrm{sec})\end{array}$ & $\begin{array}{c}\text { Turbulence } \\
\text { Intensity }(\%)\end{array}$ \\
\hline 3.4 & 1.92 & 9.9 \\
\hline 10.2 & 2.24 & 6.1 \\
\hline
\end{tabular}

The implications of the data are discussed in the full report. The normalized velocity and turbulence intensity profiles are illustrated in the full report along with models suggested by standard texts such as White (1974) and Munson et al. (1994). The velocity profile is a nearly exact match to the theoretical fully developed laminar profile. As explained in the full presentation, this match is as expected.

Closure. The LDV was successfully used to investigate pipe flow. The observed features are characteristic and consistent with other experiments and established theory.

References.

White, F. M., 1974 , Viscous Fluid Flow, 2nd ed., McGraw-Hill, New York, pp. $74-76$.

Munson, B. R., D. F. Young, and T. H. Okiishi, Fundamentals of Fluid Mechanics, John Wiley and Sons, New York, pp. 367-369. 
FROM: ME 4053 Section A7, Group 2: G. Burdell, G.-P. Burdelle, and J. Burdelo SUBJECT: Investigation of Pipe Flow Using the Laser Doppler Velocimeter

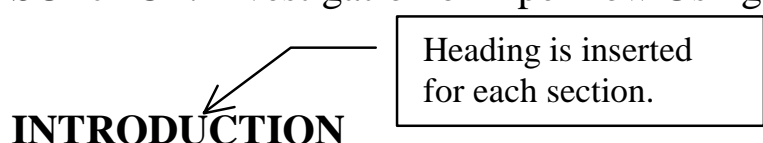

INTRODUCTION

The flow of water in a circular pipe was investigated using a Laser Doppler Velocimeter (LDV) on 9 April 1998 in the Thermal Sciencks Instructional Lab of the School of Mechanical Engineering at Georgia Tech. Velocity and turbulence intensity profiles were measured. The flow was identified as being a fully developed turbulent flow.

\section{PROCEDURE AND APPARATUS}

The water flow loop consists of a circulating pump, controls, and auxiliary piping supplying a nearly constant flow to a $38 \mathrm{~mm}$ (1.5 inch) inner diameter glass pipe. The velocity profile was conducted by traversing the measurement volume of the differential Doppler LDV (TSI System 9100) diametrically between the inner walls of the pipe at $1.27 \mathrm{~mm}$ (nominally 0.05 inch) intervals.

\section{DATA AND FINDINGS}

Velocity and turbulence intensity data were collected and are provided on the accompanying spreadsheet and some representative data are summarized in Table 1. As seen in the table the velocity increases sharply near the wall. The turbulence intensity is large near the wall and declines in the core flow.

Table 1. Representative Velocity Statistics

\begin{tabular}{|c|c|c|}
\hline $\begin{array}{c}\text { Wall } \\
\text { Distance } \\
(\mathrm{mm})\end{array}$ & $\begin{array}{c}\text { Mean } \\
\text { Velocity } \\
(\mathrm{m} / \mathrm{sec})\end{array}$ & $\begin{array}{c}\text { Turbulence } \\
\text { Intensity (\%) }\end{array}$ \\
\hline 0.43 & 1.57 & 13.2 \\
\hline 5.51 & 2.01 & 8.64 \\
\hline 8.89 & 2.31 & 6.33 \\
\hline 13.9 & 2.34 & 4.53 \\
\hline
\end{tabular}

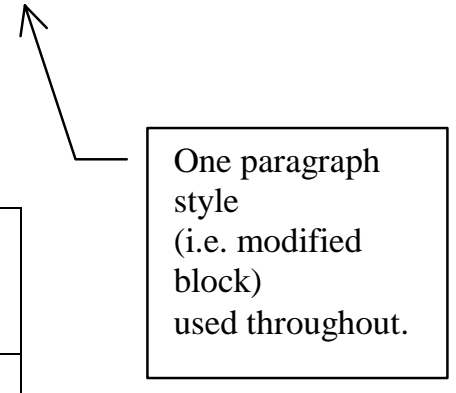

\section{Extra line skipped} between all paragraphs.

The normalized velocity and turbulence intensity profiles are illustrated in Figure 1 along with models for fully developed turbulent and laminar flows suggested by standard texts such as White (1974). The experimental velocity data show excellent agreement with the fully developed turbulent flow model. In particular the velocity rises sharply in the near wall region and continues to increase gradually in the core flow. The velocity reaches a smooth maximum at the centerline. This agreement is expected given the large experimental Reynolds number of 93,500 and the long entry length. The turbulence intensity is moderate in the core flow but high in the near wall regions. This turbulence intensity is consistent with a model of circulating turbulent 
eddies being carried along with the flow. The near wall peaks arise from interaction between the circulating eddy flow and the steep velocity gradient in these regions.

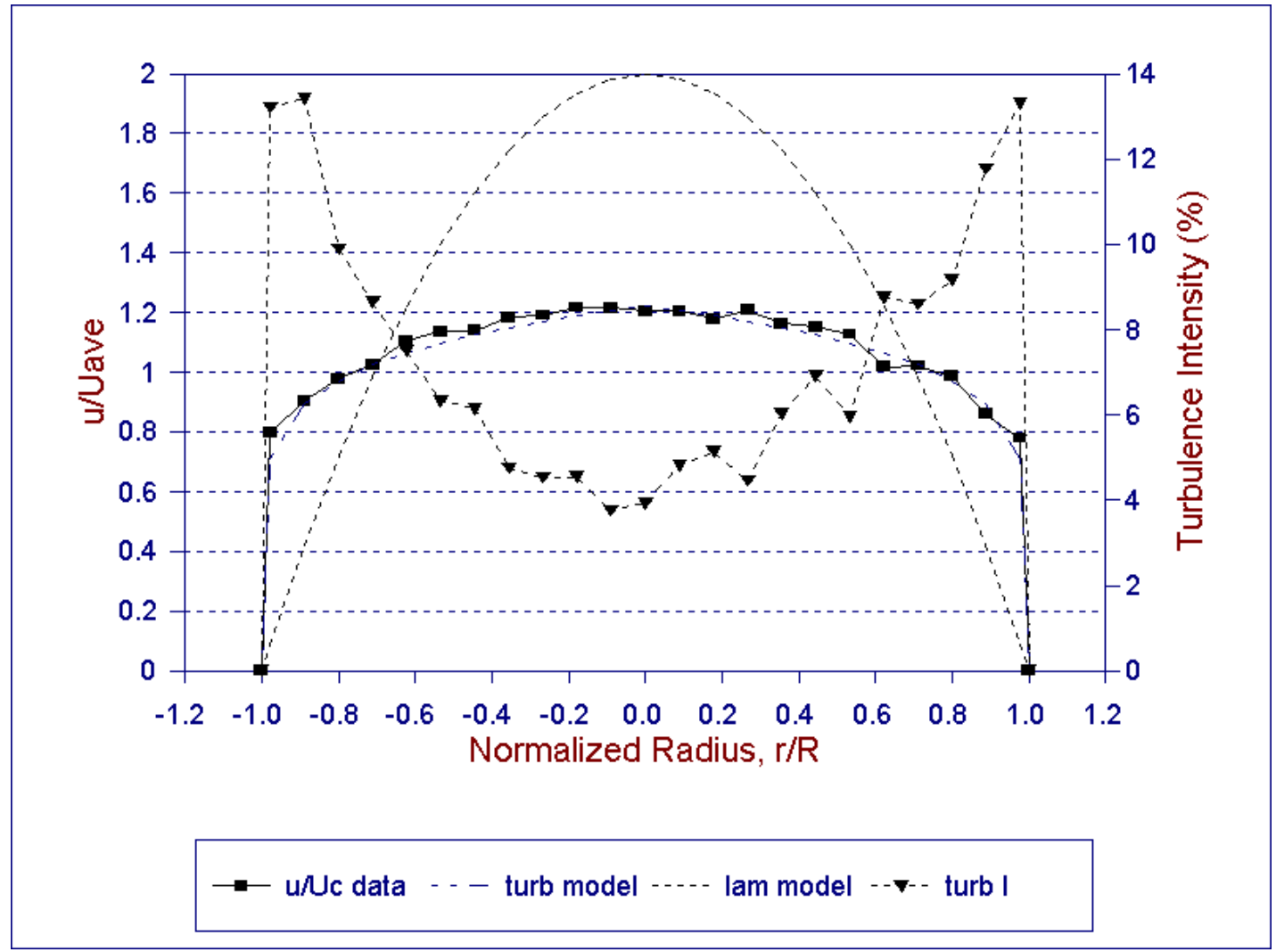

Figure 1. Profiles of Velocity (i. e., squares) and Turbulence Intensity (i.e., triangles) in Experimental Pipe Flow

\section{CLOSURE}

No new information introduced in closure.

The LDV was $\measuredangle$ uccessfully used to investigate pipe flow. The observed features are characteristic and consistent with other experiments and established theory.

\section{REFERENCE}

White, F. M., 1974, Viscous Fluid Flow, 2nd ed., McGraw-Hill, New York, pp. 74 -76. 